\title{
Design and Implementation of Home Appliance Energy Monitoring Device
}

\author{
Shereefdeen O. Sanni* \\ Department of Electrical and \\ Electronics Engineering, Federal \\ University Oye Ekiti \\ Nigeria
}

\author{
Kehinde O. Olusuyi \\ Department of Electrical and \\ Electronics Engineering, Federal \\ University Oye Ekiti \\ Nigeria
}

\author{
Ismail Mahmud \\ Department of Electrical and Computer \\ Engineering, Ahmadu Bello University \\ Zaria. \\ Nigeria
}

*corresponding author: Shereefdeen O.Sanni, shereefdeen.sanni@fuoye.edu.nh

\begin{abstract}
This paper presents the implementation of an energy monitoring device using Arduino Nano microcontroller to measure the power consumed by any individual electrical appliance in residential homes. It is also designed with the capability of sending measured electrical power parameters through SMS to owners when a request is made. The electrical energy and power are calculated based on measurements taken by Allegro ACS712 Hall effect current sensor and measured voltage over a time period. A novel feature of this device is its ability to also determine the start-up current of inductive loads. The device come in handy for homeowners who want to monitor the energy consumption of some appliances to reduce associated electricity bills. In addition, it could also be used for an energy audit of residential homes.
\end{abstract}

Keywords- ACS712 current sensor, arduino nano, energy monitoring device, SIM800L GSM/GPRS, starting current

\section{INTRODUCTION}

The increasing number of an electrical appliance in residential households has been identified as one of the fastest growing load due to consumer thirst for the latest technology in home entertainment. This is enhanced by the technological revolution in the field of power electronics which has made it possible to create energy efficient, smaller, and faster electronic devices. Despite the energy efficiency of these devices, they introduce a problem associated with increased residential energy consumption. As a result, it causes an increase in demand for oil, coal, natural gas, and other energy supply which drive major power plants. This consequently contributes to increasing pollutions from $\mathrm{CO} 2$ and other greenhouse gases emissions which are harmful to negative impacts on the environment.

Global residential electricity consumption is growing mainly due to the increasing population and improved economic climate. In Nigeria for example, average residential electricity consumption is estimated at $18-27 \mathrm{kWh}$ per capita accounting for about $60 \%$ of consumption [1]. Residential loads broadly fall under one of the following categories as lighting, cooking, laundry, entertainment, and cooling. Residential energy conservation starts with an understanding of how energy in these appliances is used and knowing how to monitor and control it for energy conservation. It is logical for homeowners to change their consumption behavior and invest wisely in consumer electronics to decrease their monthly energy consumption and electricity bill once they are aware of their energy profile. There is a need to develop an energy consumption monitoring tool to adequately monitor the amount of energy consumed by the home appliance. Over the years, different works on energy monitoring devices have been reported in already existing literature with a diverse approach of implementation.

[2] proposed a power monitoring device (PMD) which can be integrated into an Energy management system (EMS) or Smart grid. based the peer-to-peer communication, PMD can be connected to an energy grid to monitor electrical parameters such as voltage, current, real power, reactive power, apparent power, etc. However, when EMS is installed for a customer with a different requirement, the PMD often need some modification which could be time-consuming and quite expensive, thereby making it vulnerable for all type of unknown interruption.

[3] developed a smart plug energy monitoring system with controller and real-time feedback of attached device energy consumption. Key components of the design include an Ethernet module, enc28j60 for internet connection and a noninvasive type current sensor to sense the current flowing on to the device. Test results monitored through the developed Arduino-Android platform for remote monitoring of energy consumption devices showed an energy saving of $15 \%$. Similarly, [4], proposed a smart non-intrusive power consumption monitoring system using the SCT-013-030 current sensor, Bluetooth Low Energy (BLE) and factorial Hidden Markov Model algorithm (FHMM). The monitoring interface is a web-based user interface. [5] implemented a home electrical appliances control system with an energy consumption monitoring scheme using web-based application based on laravel php framework and MySQL database. The system was able to lower total energy usage of the appliances by up to $59 \%$ by cutting off the power to appliance during standby operation.

In a similar approach, [6], proposed a 3 phase energy monitoring for a single device and could also be used as an educational tool for undergraduate studies. The project which 
featured a SD card for data logging is built around the programmable interface controller (PIC), interfaced with suitable current and voltage measurement sensors. The device is capable of measuring the apparent power, voltage, and current with acceptable error. However, it is adaptable for laboratory use and limits the power measurement to a balanced three-phase power system only.

[7] presents an implementation of efficient power consumption monitoring system based on internet of things (IoT) used for a mobile app is designed to monitor all electronic appliances in home/office, continuously report their energy consumption and triggering an alarm whenever the user consumes more power through an electronic device.

Some other works developed an energy monitoring device with control capability. A Bluetooth based device for monitoring and controlling of the home appliance is presented in [8]. The system allows users to interact with their appliances to get power consumption details in real time and control connected devices by sending a specified command through a Smartphone. [9] proposed an energy management system based on wireless sensor networks and an intelligent home gateway. While the wireless sensors are used for sensing and transmitting electricity data, remote monitoring and control of home appliances are delivered through the intelligent home gateway. In both systems, energy savings is enhanced by monitoring and controlling home appliances through a remote interface.

This work focuses on the design of an energy monitoring device for home appliances with GSM capability. The system uses measured voltage and current sensor integrated with an Arduino Nano board to determine the energy consumption of connected loads. An SMS containing measured parameters could also be sent to the owner when a request is made a compromise in the original state.

\section{MATERIALS AND METHOD}

This paper proposes an energy monitoring system with GSM capability. The energy monitoring process begins by sensing the real-time current values and the voltage across its terminals to compute the instantaneous power and energy over time. The result will be calculated and displayed on the LCD or sent to the device owner through a mobile phone if requested. The methods employed involves designing the hardware components of the circuit diagrams while as well as the development of the required software to drive this system. The structure of the system along with its main components illustrated in figure 1.

\section{A. Hardware Development}

\section{Current Sensing Unit}

The Allegro ACS712 Hall effect current sensor is used to monitor the current in real time. It is based on the Hall-effect principle, in which a current carrying conductor is placed into a magnetic field to generate a voltage across its edges perpendicular to the directions of both the current and the magnetic field. The magnitude of this voltage is proportional to the current and magnetic field and within the range of few microvolts. The ACS712 is available in the form of a surface mount SOIC8 package which consists of an on-chip signal conditioner and filter circuit to stabilize and enhance the induced Hall voltage to an appropriate level so that it could be measured through an ADC channel of a microcontroller. The pin diagram and schematic of ACS712 device and its typical application circuit are illustrated in figure 2. The sensor leads are isolated from the copper conduction paths (pins 1, 2 and 3, 4) thus eliminating the possibility of damage when dealing with high voltage conduction.

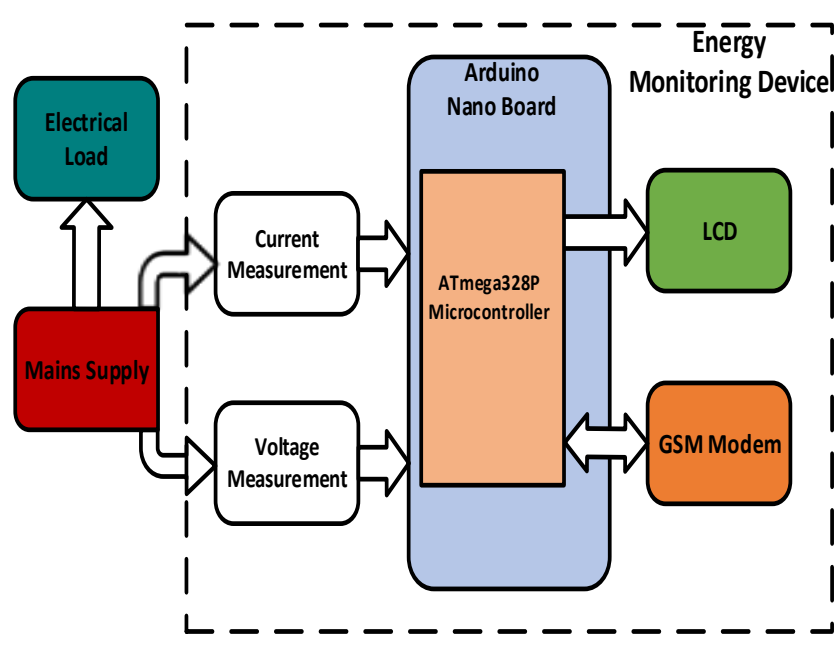

Figure 1: System configuration

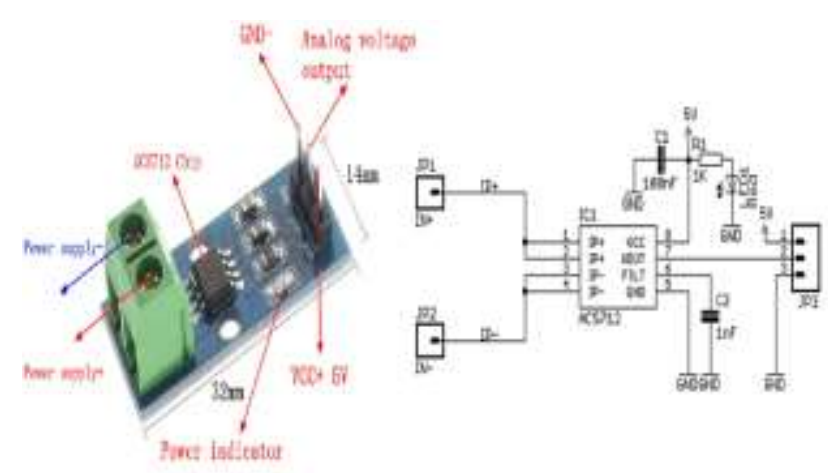

Figure 2: Allegro ACS712 Hall effect current sensor

\section{GSM/GPRS Module}

The SIM800L GSM/GPRS module can be described as a miniaturized cell phone adaptable to most electronic project. With an operating voltage in the range between $3.4 \mathrm{~V}-4.4 \mathrm{~V}$, it is an ideal candidate for embedded systems since it includes pins required for communication with a microcontroller over UART. To avoid frequent shut down of the module, an external power supply is required to supply this range of voltage along with a $2 \mathrm{~A}$ surge current. It accepts any activated micro SIM card with capabilities which includes amongst others; ability to send and receive SMS messages, make and receive voice calls using an external $8 \Omega$ speaker \& electret microphone, send and receive GPRS data, etc. Depending on the state of operation, power demand from the module can be relatively high as it draws a maximum current of about $200 \mathrm{~mA}$ during transmission burst, $216 \mathrm{~mA}$ during phone calls and $80 \mathrm{~mA}$ during network transmissions. Figure 4 illustrates the front and rear view of the SIM800L GSM module. 

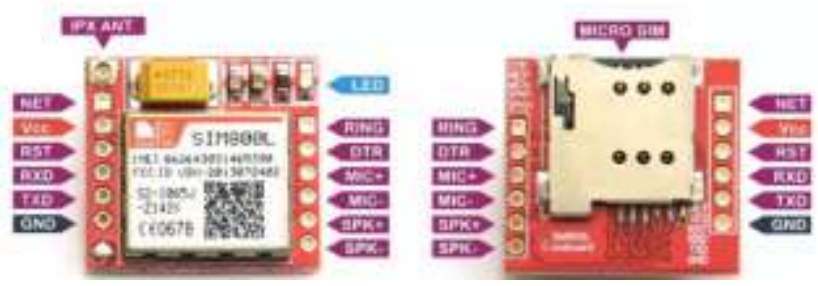

Figure 3: SIM800L GSM showing the SIM holder and GSM Antenna

\section{Microcontroller}

At the heart of the EMD is the Arduino Nano board with inbuilt ATmega168/ATmega328 microcontroller. Its choice is based on its compact nature and a user-friendly microcontroller board with ease of programming. The Nano board is available in a 32 pin plastic quad flat pack (PQFP) with 14 digital input/output pin, 8 analog input pins, input voltage range of $6-20 \mathrm{~V}$ and a Mini-B USB port. The USB port is used for powering, programming and serial monitoring of the board. Although the Nano board can also be powered by a $6-20 \mathrm{~V}$ unregulated external power supply (pin 30) or the $5 \mathrm{~V}$ regulated external power supply (pin 27), it automatically selects the highest voltage source. A unique feature of this board is that it is designed in a way that allows it to be reset by software running on a connected computer.

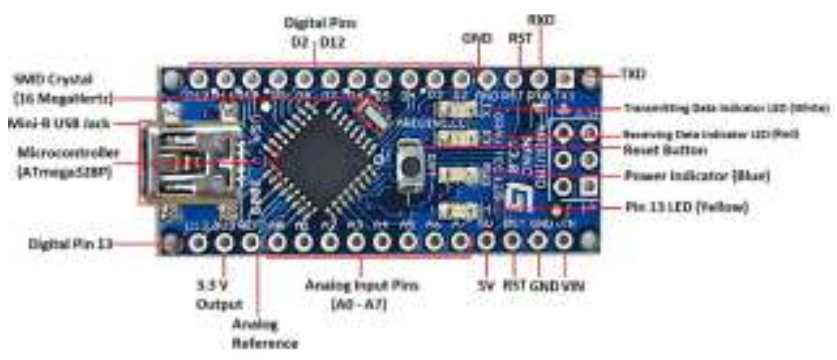

Figure 4: Arduino Nano board with ATmega328 microcontroller

\section{B. Software Development}

The E-M-D hardware is made functional by a software design used in controlling the embedded Arduino microcontroller. The Arduino Nano microcontroller which features an ATmega328P processor is programmed via the Arduino integrated development environment (IDE); an open source IDE written majorly in java and processing for writing microcontroller codes often referred to as sketches. Figure 5 illustrates a section of the code within the IDE.

\section{IMPLEMENTATION, TESTING, AND RESULTS}

The entire hardware system and software programming were simulated on Proteus software to confirm its functionality. Subsequently, the program which was burnt unto the microcontroller unit of the Arduino nano board was assembled with other hardware components of the system on a Vero board and placed in the casing. The system works by continuously monitoring the current drawn by the load through the current sensor and voltage measurement. These measurements will be processed in the microcontroller and the results displayed on the LCD. If a request is made from a preconfigured GSM phone it sends an SMS to the owner. Figure 6 illustrates the circuit diagram while Figure 7 shows the implemented hardware prototype of the system.

To validate the readings obtained with the system, three different tests were done on a number of common residential load for conformance vis-a-vis the following objectives:

- Ability to measure applied voltage and the current (starting and running) of a connected appliance in real time.

- Calculate the power and energy consumption while displaying energy consumption on the LCD screen

- Send the measured and calculated energy parameters to a target phone number upon query via the SIM800L GSM module.

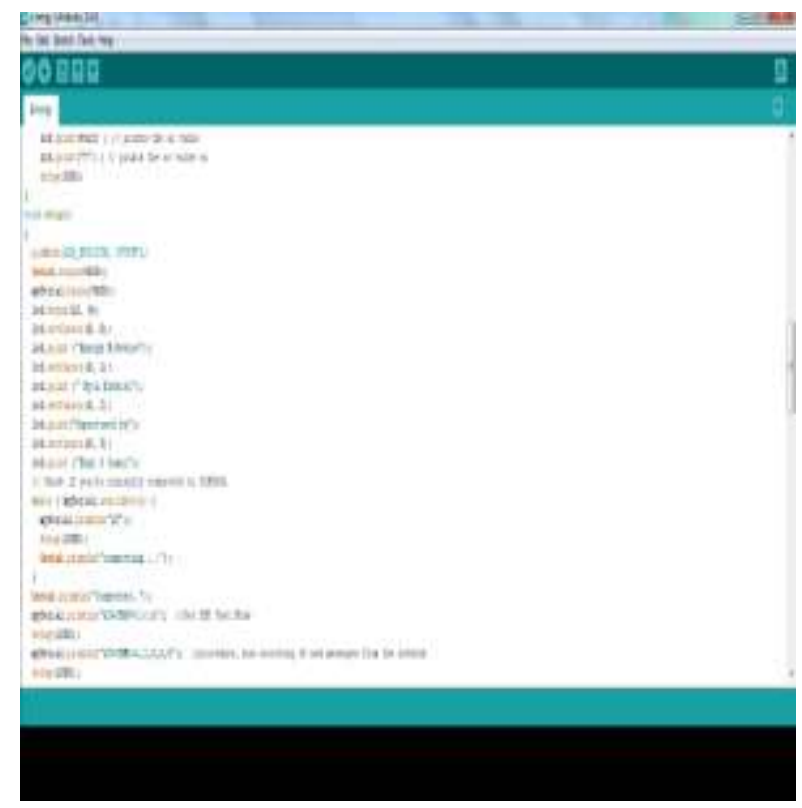

Figure 5: Screenshot of the software development interface

\section{A. Voltage, Current and Energy Measurement Test}

Although the E-M-D device was designed to measure and use the running current of the attached load to determine the power and energy, it also has the unique capability of recording the start-up current of inductive loads. The following steps are involved in measuring the start-up current:

- Ensuring the E-M-D device is powered off and connected to an AC power supply

- Connecting the desired appliance to be measured whilst switching on the E-M-D output without switching on the AC source. This ensures that power is supplied to the target appliance immediately the EM-D is switched on

- Switching on the E-M-D to allow the device to obtain the start-up current and other energy parameters.

Figure. 8 Illustrates the readings of the device displaying voltage and the start-up current and other parameters of a refrigerator The energy readings are obtained from the current and voltage readings, calculated by the microcontroller and 
the resulting values are displayed on the integrated LCD

screen.

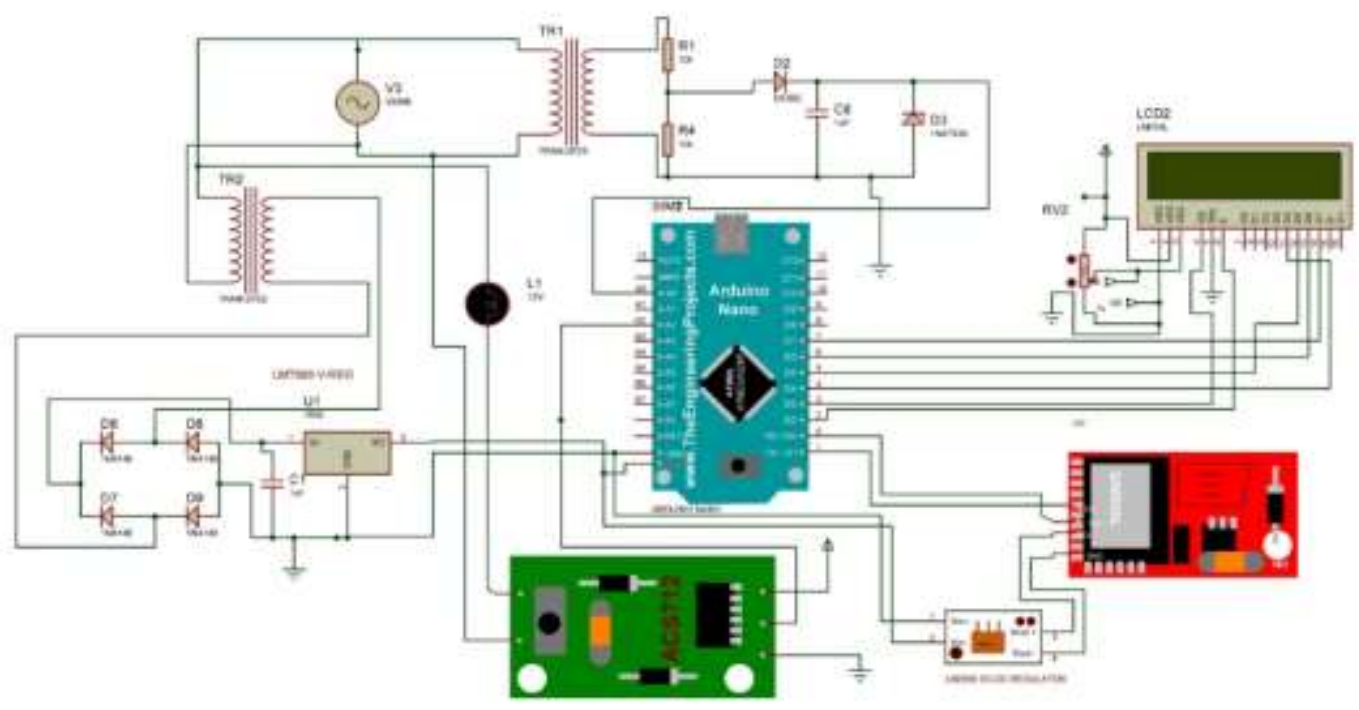

Figure 6: Circuit diagram of the system

Table 1: Measurements for Selected home appliance

\begin{tabular}{|c|c|c|c|c|c|c|c|c|}
\hline \multirow{2}{*}{ S/N } & \multirow{2}{*}{ Electrical appliances } & \multicolumn{3}{|c|}{ Manufacturer rating } & \multicolumn{4}{c|}{ Measured value } \\
\cline { 3 - 9 } & & $\begin{array}{c}\text { Power } \\
(\mathbf{W})\end{array}$ & $\begin{array}{c}\text { Current } \\
(\mathbf{A})\end{array}$ & $\begin{array}{c}\text { Voltage } \\
(\mathbf{V})\end{array}$ & $\begin{array}{c}\text { Power } \\
(\mathbf{W})\end{array}$ & $\begin{array}{c}\text { Current } \\
(\mathbf{A})\end{array}$ & $\begin{array}{c}\text { Starting } \\
\text { current } \\
(\mathbf{A})\end{array}$ & $\begin{array}{c}\text { Voltage } \\
(\mathbf{V})\end{array}$ \\
\hline 1 & Iron & $1100 \mathrm{~W}$ & - & $240 \mathrm{~V}$ & $828.33 \mathrm{~W}$ & $4.06 \mathrm{~A}$ & - & $204.1 \mathrm{~V}$ \\
\hline 2 & Standing fan & $65 \mathrm{~W}$ & - & $230 \mathrm{~V}$ & $50.07 \mathrm{~W}$ & $0.24 \mathrm{~A}$ & $0.50 \mathrm{~A}$ & $204.6 \mathrm{~V}$ \\
\hline 3 & Blender & $350 \mathrm{~W}$ & - & $230 \mathrm{~V}$ & $337.9 \mathrm{~W}$ & $1.55 \mathrm{~A}$ & $2.10 \mathrm{~A}$ & $218 \mathrm{~V}$ \\
\hline 4 & Laptop & $336 \mathrm{~W}$ & - & $100-240 \mathrm{~V}$ & $124.64 \mathrm{~W}$ & $0.76 \mathrm{~A}$ & - & $164.0 \mathrm{~V}$ \\
\hline 5 & Chest freezer & $1300 \mathrm{~W}$ & - & $220 \mathrm{~V}$ & $1141.09 \mathrm{~W}$ & $5.62 \mathrm{~A}$ & $9.95 \mathrm{~A}$ & $204.3 \mathrm{~V}$ \\
\hline 6 & TV & $56 \mathrm{~W}$ & - & $100-240 \mathrm{~V}$ & $74.05 \mathrm{~W}$ & $0.36 \mathrm{~A}$ & - & $206.1 \mathrm{~V}$ \\
\hline 7 & Radio & $21.5 \mathrm{~W}$ & - & $220 \mathrm{~V}$ & $28.47 \mathrm{~W}$ & $0.14 \mathrm{~A}$ & - & $205.9 \mathrm{~V}$ \\
\hline 8 & Portable speaker & $60 \mathrm{~W}$ & - & $110-220 \mathrm{~V}$ & $26.39 \mathrm{~W}$ & $0.13 \mathrm{~A}$ & - & $205.6 \mathrm{~V}$ \\
\hline
\end{tabular}




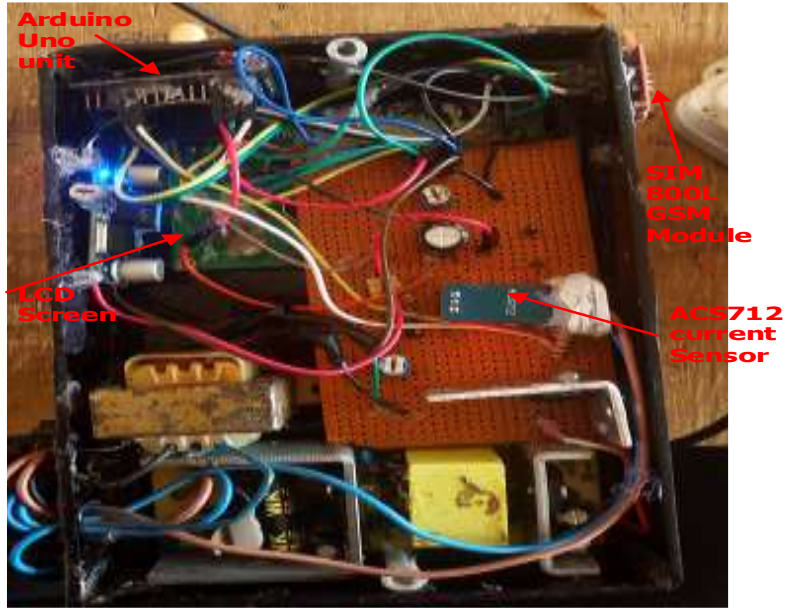

Figure 7: Hardware prototype after implementation

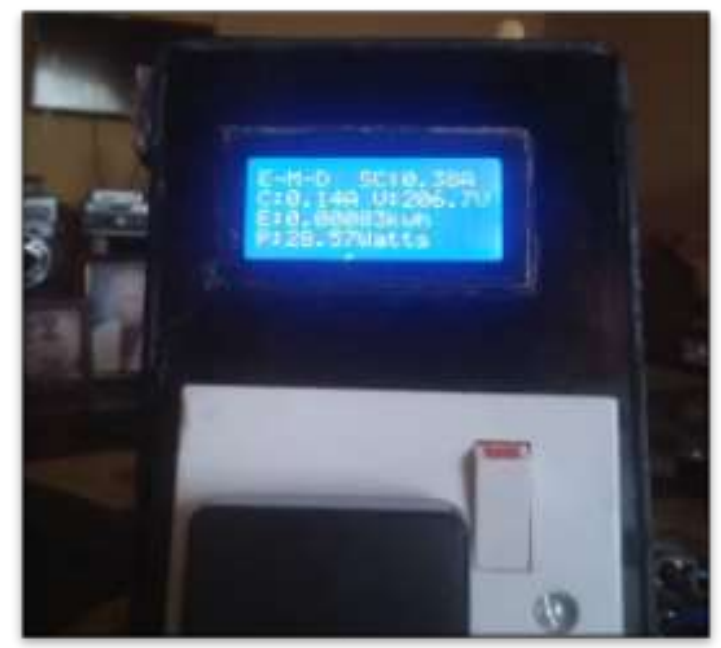

Figure 8: Typical display of measurements taken for a standing fan

Energy measurements were taken for some other common home appliances and the results are as shown in Table 1. It gives a comparison of the actual rating of a device with measured values. It is observed that for most home appliance the measured value follows the manufacturer ratings with deviations based on the utility supply voltage. However, for appliances whose load type can best be described as inductive; the measured starting and running current responded very differently. Taking a look at the standing fan, blender and chest freezer, it is observed that measured current parameters are far from ideal since most inductive devices have to start currents that are at least twice its running current. This as a result of a drop in utility supply voltage which resulted in a lower starting current and a higher running current.

\section{B. Remote Access Test Via Mobile Phone}

The energy parameters of a connected appliance can be accessed remotely by sending a pre-programmed SMS keyword to the phone number of SIM card inserted in the GSM module.

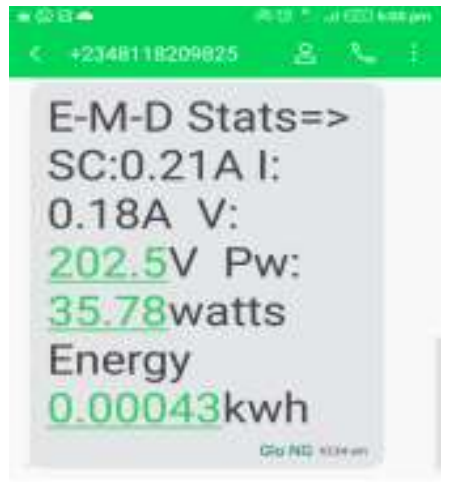

Figure 9: SMS Energy Status Report of E-M-D for a connected appliance

However, it is required that the desired SIM card is preloaded with sufficient SMS airtime credit or subscribed to an unlimited data plan to ensure delivery of sent data to the target user by the device. Figure. 9 Shows a sample SMS of reading received by a user when the device is queried for readings.

\section{CONCLUSION}

Reduction in power consumption is the objective of modern home electrical appliance design. Understanding how much energy these devices consume raises customer awareness of the need for energy conservation. In this paper, we present the implementation of an energy monitoring device with GSM capability which can monitor the electrical power parameters of a home appliance such as start-up current, voltage, power, and energy consumption. The device uses measured values of voltage and current to compute the power and energy consumed. Test conducted on the device using common residential appliance show high reliability when compared with manufacturers rating. Additionally, a query of measurements reading of the device through a preconfigured phone number was adequately replied. The device is a compact and cost-effective system that could find application in an energy audit of residential homes while also allowing homeowners to control energy use and manage electricity bills.

\section{ACKNOWLEDGMENT}

the authors would like to acknowledge Ayodeji Ezekiel for providing the home appliances used in testing this device. 


\section{REFERENCES}

[1] Olaniyan, K., McLellan, B., Ogata, S., \& Tezuka, T, "Estimating Residential Electricity Consumption in Nigeria to Support Energy Transitions. Sustainability", 10(5), 2018.

[2] Tang, G., Zhuo, Y., Wu, J., Yu, Y., \& Hu, F, "Power Monitoring Device based on Peer-to-Peer Communication", In 2010 Asia-Pacific Power and Energy Engineering Conference, IEEE, 2010.

[3] Shajahan, A. H., \& Anand, A, "Data acquisition and control using Arduino-Android platform: Smart plug. In 2013 International Conference on Energy Efficient Technologies for Sustainability", IEEE, 2013.

[4] Juhana, T., \& Irawan, A. I, "Smart non intrusive power consumption monitoring system. In 2016 10th International Conference on Telecommunication Systems Services and Applications (TSSA)", IEEE, 2016.

[5] Putra, L., Michael, Yudishtira, \& Kanigoro, B, "Design and Implementation of Web-Based Home Electrical Appliance Monitoring, Diagnosing, and Controlling System", Procedia Computer Science, 59, 34-44. 2015.

[6] Elamvazuthi, I., Khan, M. A., Shaari, S. B. B., Sinnadurai, R., \& Amudha, M, "Electrical power consumption monitoring using a realtime system", Sustainable Utilization and Development in Engineering and Technology (STUDENT), 2012 IEEE Conference, pp. 295-298, 2012.

[7] Surya, J., \& Perumalraja, R, "A Real-Time Iot Implementation for Efficient Energy Consumption", International Research Journal of Engineering and Technology, 4(6), 1525-1528, 2017.

[8] Anupama, S., \& Mahadevaswamy, U. B, "Design and Development of a Smart Device for Energy Monitoring and Control of Domestic Appliances: An Android Application", International Journal of Image, Graphics and Signal Processing, 10(1), 36-46, 2018.

[9] Kim, W. H., Lee, S., \& Hwang, J, "Real-time Energy Monitoring and Controlling System based on ZigBee Sensor Networks", Procedia Computer Science, 5, 794-797, 2011. 